\title{
Role of gp91phox Homolog Nox1 in Induction of Premalignant Spindle Phenotypes of HPV 16 E6/E7-Immortalized Human Keratinocytes
}

\author{
Walee Chamulitrat \\ Internal Medicine IV, Department of Gastroenterology and Infectious Disease, \\ University Heidelberg Hospital, Germany \\ E-mail: Walee.Chamulitrat@med.uni-heidelberg.de
}

Received February 24, 2010; Revised June 3, 2010; Accepted June 6, 2010; Published July 20, 2010

The NADPH oxidase (Nox) family of superoxide- and hydrogen peroxide-producing proteins has been recognized as important for signal transduction that regulates receptor-mediated functions, including cytoskeleton remodeling, cell proliferation, migration, differentiation, and cell death. Nox1 was the first of the Nox catalytic subunits to be cloned and shown to induce tumorigenic conversion of mouse fibroblasts. While Nox1 has been shown to be expressed in human colon and prostate cancers, however, limited studies have demonstrated the involvement of Nox1 in an early step of cell transformation. The aim of this review is to provide an overview on the role of Nox1 in cancer, as well as the contribution of our studies to demonstrate the involvement of Nox1 on neoplastic progression of human keratinocytes beyond the immortalization step. The generation of spindle phenotypes concomitant with anchorage-independent growth and invasiveness will be highlighted and discussed in relation to the possible role of Nox1 in epithelial-mesenchymal transition. Understanding these mechanisms may provide insight into Nox1 and redox signaling components as potential therapeutic targets to inhibit tumor progression.

KEYWORDS: NADPH oxidase, reactive oxygen species, epithelial cytokeratin, vimentin, tumor progression, invasion, MAPK activation, inducible nitric oxide synthase

\section{INTRODUCTION}

Reactive oxygen species (ROS) are conventionally thought to be cytotoxic and mutagenic, and in high levels they induce cell death, apoptosis, and senescence. In contrast, ROS at low levels function as signaling molecules to mediate cell growth, migration, differentiation, and gene expression. Elevated levels of ROS, namely, superoxide and hydrogen peroxide, are found in human tumor cells[1] and malignantly progressed keratinocytes[2]. Mitochondrial ROS, which are produced by the respiratory chain, have been thought to act as prosurvival and prodeath signals exerting a decisive control over several biochemical cascades, leading to cell death and the intrinsic pathway of apoptosis[3]. ROS could 
serve as an endogenous source of DNA-damaging agents to promote genetic instability. In addition, several mitochondrial DNA mutations were reported in tumors and the construction of cybrids recently demonstrated their role in the control of tumor progression[4]. Besides mitochondria, enzymes involving redox regulation have also been implicated in cancer, including polyamine oxidases[5], lipoxygenases[6,7], and NADPH oxidase gp91phox (Nox) homologs[8]. Nox proteins are membraneassociated, multiunit enzymes that catalyze the reduction of oxygen using NADPH as an electron donor. Nox proteins produce a superoxide radical by a single electron reduction. NADPH oxidase historically is known to be the source of ROS during phagocytosis. In the past 15 years, Nox family members (Nox 1-5 and Duox 1/2) present in a variety of tissues have been identified as important mediators of normal physiologic functions that include innate immunity, signal transduction, and biochemical reactions; for example, to produce thyroid hormone[9]. With the high biochemical reactivity of ROS, Nox enzymes have been implicated in a wide variety of pathologies and diseases, particularly those associated with inflammation, aging, and progressive degenerative changes in cells and organ systems. Nox-derived ROS are involved in chronic diseases that tend to appear later in life, including atherosclerosis, hypertension, diabetic nephropathy, lung fibrosis, Alzheimer's disease, and cancer[10]. Nox enzymes may thus be the targets of drugs for treatment of these chronic diseases[11]. Compared with other Nox isoforms, the most intensively studied, Nox1, has been shown to be highly expressed in human colon and prostate cancers $[8,12,13]$. This review summarizes our findings to implicate Nox 1 in preneoplastic progression by an induction of epithelial-mesenchymal transition (EMT) of immortalized human keratinocytes. Signaling pathways induced by Nox1 in alterations of cytoskeletal remodeling will be discussed.

\section{NOX1 AS A SOURCE OF ROS IN CANCER}

During 1999-2000, three papers reported the first sequence of gp91phox homolog cDNA, all cloned from normal human colon[8,14,15]. This gene was formally called Mox1 (mitogenic oxidase1) and later renamed to Nox1. All Nox isoforms are expressed on the mRNA level in fetal tissues more abundantly than in adult tissues, and Nox 1, 2, 4, and 5 mRNAs are expressed in a variety of human cancer cell lines, indicating an association with cancer development[16]. Nox1, a homolog of gp91phox, is described as highly expressed in human colon, but at lower levels in vascular smooth muscle, endothelial cells, uterus, placenta, retinal pericytes, neurons, astrocytes, and microglia. Nox1 is capable of mediating tumorigenic conversion when overexpressed in rodent NIH3T3 fibroblasts[8]. In these cells, overexpression of Nox1 increases tumorigenic potentials and catalase overexpression reverses tumor promotion[17]. This indicates that hydrogen peroxide generated secondarily by the enzyme serves as the transformation signal.

For the case of human epithelial cancer cells, overexpression of Nox1 increases tumorigenic potentials of the DU-145 human prostate cancer cell line[18], which is supported by Nox1 presence in human prostate cancer tissues[13]. Prostate tumors are significantly more likely to have Nox1 staining than benign prostate tissues[19]. Nox1 mRNA is present in both primary and transformed human colonic epithelial cells[20], while Nox1 mRNA and protein are overexpressed in human colonic tumors compared with paired normal tissue as early as the adenoma stage with no correlation of expression level with tumor stage[12]. Other data also indicated that Nox1 may induce differentiation of colonic cancer cells HT29 [21], and thus is highly expressed in well-differentiated colon cancer[22]. Nox1 may play a distinct role during cell differentiation of normal and tumor tissues. Nox1 not only plays a role in colonic carcinogenesis, but also in innate immune response of the gastrointestinal tract[23]. Accordingly, Nox1 detected in colon epithelial crypts and on the luminal surface is implicated as playing a role in host defense function[24]. In addition to the known epithelial localization, lymphocytes are a novel site of Nox1 expression, where it may potentially be involved in the pathogenesis of inflammatory bowel diseases[24]. It is known that activation of NADPH oxidases in intestinal lymphocytes generate ROS[25]. In this light, additional insights have been raised that Nox1-generated ROS in lymphocytes may induce colonic inflammation, which predisposes the colon for neoplastic progression. In addition to colon and prostate cancers, Nox1 also stimulates proliferation of breast and ovarian cancer cells by mediating a 
cross-talk with mitochondria[26]. In mammalian epithelial cells, chronic oxidative stress induced by Nox1 appears to saturate cellular DNA repair capacity and cause significant genomic instability, which may lead to neoplastic progression[27].

\section{Molecular Structure and Regulation of Nox1}

The Nox1 gene contains 564 amino acids[8]. Two splicing forms of Nox1 were described as Nox-1S (shown to mediate $\mathrm{H}^{+}$current) and Nox-1L-tv (Nox1 long-truncated variant)[14]. However, Nox-1S was later identified as a cloning artifact during RNA amplification[28]. Nox-1L-tv has 49 amino acids (residues 431 to 488 containing one of the four NADP-binding sites) in exon 11 missing from the bona fide Nox1. This missing NADP-binding site containing ${ }^{435}{ }^{\text {FYWICRE }}{ }^{441}$ is highly conserved and shared by other Nox enzymes[14]. Nox-1L-tv is detected in human colon, uterus, prostate, and Caco-2 cells. While the function of Nox-1L-tv (or Nox1-tv) is not known, it was reported that Nox1-tv is not a functional enzyme as it did not support ROS generation in a presence of Nox1-supportive cofactors (NoxO1 and NoxA1)[29,30,31]. Thus, the exon 11-deleted Nox1-tv transcript does not encode functional oxidase despite its abundance in various tissues.

Nox1 contains six transmembrane domains (Fig. 1). Oxidase activity occurs when NADPH binds to Nox 1 on the cytosolic side, where it transfers its electrons to FAD and hemes, and finally to oxygen on the outer membrane surface to form a superoxide radical. Nox1 associates with the membrane subunit p22phox, which is necessary for Nox1 activation[32]. In a similar manner as gp91phox (Nox2), Nox1 can interact with p47phox and p67phox, but is most highly activated by the respective homologs NoxO1 and NoxA1[29,30,31]. In contrast to p47phox, NoxO1 is constitutively associated with Nox1. Similar to Nox2 activation, NoxA1[33] and GTP-activated Rac1 membrane translocation[34,35] are required for Nox1 activation and initiation of superoxide generation.

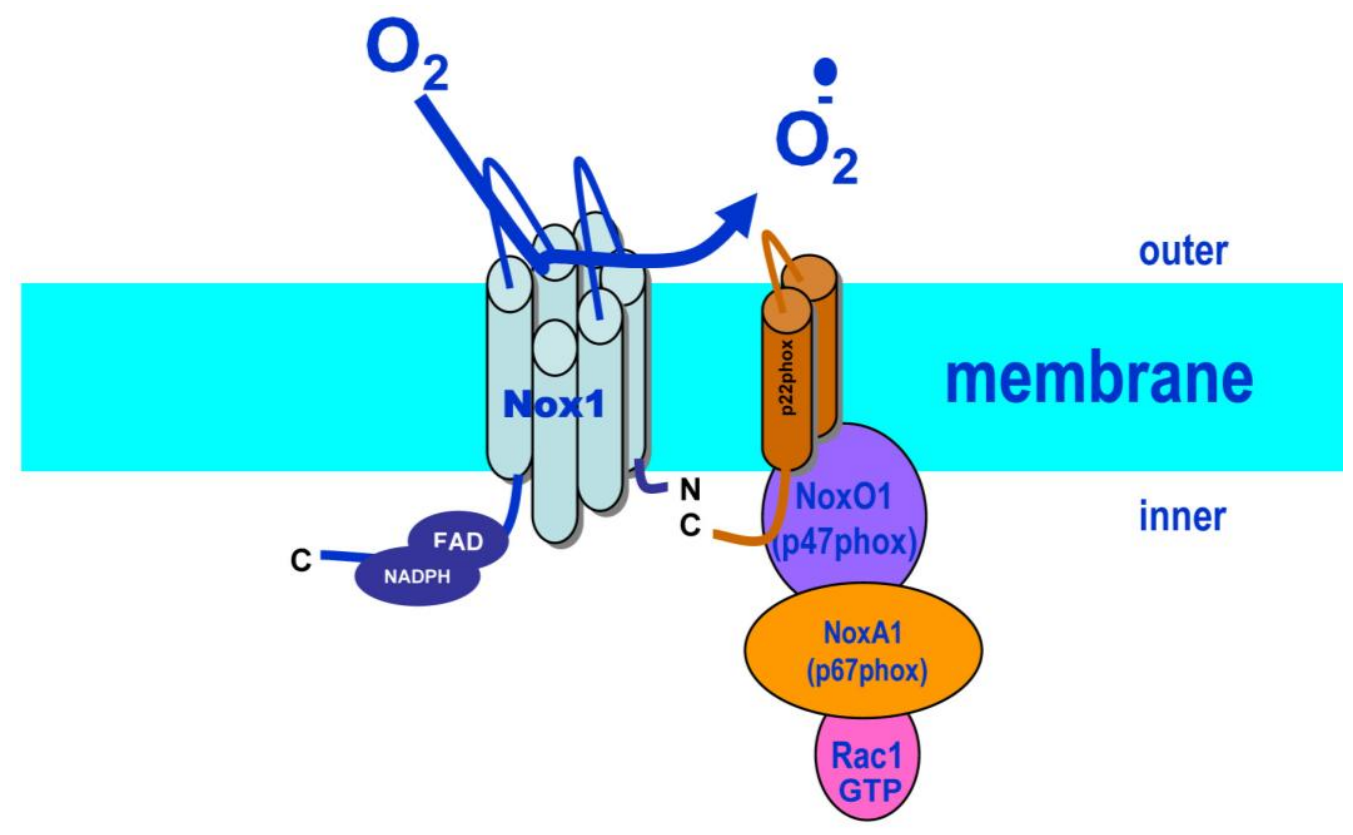

FIGURE 1. Nox1 and its regulatory subunits NoxO1, NoxA1, and Rac1, as well as the assembly factor p22phox. 


\section{Subcellular Localization of Nox1}

Depending on cell type, various Nox1 localizations have been reported. In the plasma membrane fraction from Caco-2 human colon carcinoma cells, active Nox1 endogenously colocalizes with its assembly factor p22phox and regulatory components NoxO1, NoxA1, and Rac1[33]. In intermediate transformed keratinocytes, we showed that Nox1 was found to have a nuclear localization with some cytoplasmic distribution[36]. In vascular smooth muscle cells, distribution of Nox1 on plasma membrane, specifically caveolae, as well as in the nucleus has been reported[37]. By forced expression, Nox1 is found to be localized on the plasma membrane[38,39]. It appears that the very N-terminal part of Nox1 determines subcellular localization, whereas the cytosolic tail regulates activity[39]. It is conceivable that Nox 1 localization on the specialized microdomain of plasma membrane caveolae and lipid rafts supports activation of the epidermal growth factor receptor that resides within lipid rafts. Compartmentalization of Nox1 within lipid rafts in neoplastic cancer cells may represent a unique mechanism for hyperproliferative growth. This hypothesis has been tested using our model EPI and FIB cell lines (Chamulitrat, unpublished data).

\section{Signal Transduction in Human Cancer Induced by Nox1}

Before the discovery of Nox1, ROS generation from NADPH oxidase had already been described in nontransformed and transformed human keratinocyte cell lines[40,41]. Signal transduction in transformed mouse and human keratinocytes involves an activation of activator protein 1 (AP-1) and nuclear factor kappaB $(\mathrm{NF}-\kappa \mathrm{B})$ transcription factors that mediate tumor promotion and carcinogenesis[42]. Downregulation of AP-1 and NF-kB[43] or the removal ROS by catalase[44] suppresses development of tumorigenic phenotypes. Since the discovery of Nox1, a number of studies have supported the role of Nox1 as a mitogenic oxidase in mediating cell proliferation and migration of preneoplastic and cancer cells. Hydrogen peroxide generated by Nox1 mediates cell growth and transformation of NIH3T3 fibroblasts[17], and induces angiogenic switch of human prostate cancer cells[18]. Nox1 targets cyclin D1, which regulates the cell cycle[45]. Accordingly, overexpression of Nox1 increases proliferation concomitant with increased cyclin D1 and extracellular signal regulated kinase (ERK1/2) activity[46].

In mouse fibroblasts, the activated Ras oncogene has been shown to up-regulate Nox 1 constitutively by a mechanism of GATA-6 phosphorylation by MEK-ERK, and these processes are necessary for its oncogenic properties[47]. Nox1-generated oxidants in Ras-transformed cells mediate down-regulation of the Rho activity, resulting in disruption of stress fibers and focal adhesions[48]. The down-regulation of Rho activity involves oxidative inactivation of the low-molecular-weight protein-tyrosine phosphatase and a subsequent elevation in the tyrosine-phosphorylated active form of p190RhoGAP, the direct target of the phosphatase[48]. Data in this study are consistent with those showing a correlation between activating Ras mutation and Nox1 overexpression in human colon cancers[12]. Nox1 activity is required for cell growth and survival of a subset of cancer cells, at least in part by activation of proliferative signals, e.g., MAP kinase[47] or c-Src[49]. Upstream of Nox1, ROS production in Caco-2 cells has been shown to be due to the sequential EGF-induced activation of PI3K/ $\beta$ Pix and then Rac1, which then binds to Nox1 to stimulate its oxidase activity[38].

Nox 1 has been recently implicated in cell migration of colon adenocarcinoma cancer cells[50]. Nox 1 activation by arachidonic acid occurs through 12-lipoxygenase and protein kinase $\mathrm{C}$ delta, and controls cell migration by affecting integrin $\alpha-2$ subunit turnover[50]. Physiologically, Nox1 has been shown to control the directional migration of normal colon epithelial cells[51]. In nonepithelial vascular smooth muscle cells, Nox1 plays a role in cytoskeletal remodeling upon PDGF or FGF treatment, and downstream events involve phosphorylation of cytoskeletal proteins, such as actin, cofilin, and paxillin[52,53]. A recent study has shown that Nox1-dependent ROS contribute to cell invasion by regulating matrix metalloprotease-9 (MMP-9) and cell migration[54]. Nox1 siRNAs inhibit the activation 
of IKK $\alpha$ kinase, thus suppressing the NF- $\kappa \mathrm{B}-$ dependent MMP-9 promoter activity as well as epidermal growth factor-stimulated migration[54].

\section{CONSTITUTIVE EXPRESSION OF NOX1 IN IMMORTALIZED HUMAN KERATINOCYTES}

The role of Nox1 in human cancer has usually been studied in fully transformed cells such as colonic and prostate cancer cells. Research in our laboratory has addressed the role of Nox1 at early steps of transformation of human keratinocytes at the step beyond immortalization. In our initial studies, we observed the presence of Nox1 in spontaneously immortalized HaCaT and human gingival mucosal HPV 16-immortalized keratinocytes (GM16)[55]. Both HaCaT and GM16 cells expressed the phagocyte oxidase cytosolic proteins Rac1, p40phox, and p67phox. The catalytic flavoheme protein subunit of HaCaT membranes was similar to that of neutrophils. HaCaT membranes, which expressed p22phox, showed an absorbance peak at $558 \mathrm{~nm}$ indicative of a b-type cytochrome. For kinetic studies, $\mathrm{V}_{\max }$ values of NADPH oxidase activity of HaCaT membranes were 20 -fold lower than those reported for phagocytic oxidase. $\mathrm{K}_{\mathrm{m}}$ for NADPH of keratinocyte membranes was higher than that of neutrophil membranes by a factor of two. These kinetic values bolster the notion that keratinocyte NADPH oxidase generates low levels of superoxide, but in a constitutive manner. At mRNA levels, both GM16 and HaCaT cells expressed Nox1, Nox2, and Nox4, while HaCaT cells expressed very low levels of Nox1 mRNA. At protein levels, Nox1 was readily detected in HaCaT, but was nearly undetectable in GM16 cells. This indicates differential rates of Nox1 RNA translation in these two cell lines. Translation to Nox 1 protein appears to be more efficient in HaCaT cells than GM16 cells. HaCaT cells are normally cultured in DMEM containing $1.5 \mathrm{mM} \mathrm{Ca}^{+2}$, and GM16 cells are cultured in keratinocyte growth medium (KGM) containing $0.05 \mathrm{mM} \mathrm{Ca}^{+2}$. It is speculated that Nox 1 protein translation may be accelerated by calcium because Nox1 activation is shown to be mediated by intracellular calcium[56]. From these observations, we concluded that Nox1 may a play a role in inducing proliferative advantage under high calcium, which is a differentiation condition of human keratinocytes.

$\mathrm{HaCaT}$ cells carry genetic abnormalities from spontaneous immortalization and were identified as a pretransformed phenotype. Significant Nox1 protein expression was found, in non- or pretransformed $\mathrm{HaCaT}$ cells, in about the same extent as cancer Caco-2 or HT-29 cells (all proliferate in high-calcium medium). This suggests that Nox1 may render resistance against calcium-dependent differentiationinduced cell death during a pretransformation step. This property is a known criterion for selection of more progressive neoplastic phenotypes[57]. It is known that rodent cells, such as NIH3T3 fibroblasts[58] or rat liver epithelial cells[59], can be easily transformed even upon subculturing at high density. Transformation of human epithelial cells is rare, but requires multiple steps[60]. We therefore adopt this technique in selecting neoplastic cells by culturing them in DMEM containing high calcium, and this is one of the steps in the multistep transformation of human epithelial cells. Calcium in the medium can increase telomerase activity; hence producing immortalized cell lines capable of growing in DMEM[61]. Such selection has been described previously during inhibition of terminal differentiation upon transfection of oncogene Ras[62], HPV 16 E6[63], or treatment with phorbol esters[64].

\section{CHRONIC ETHANOL EXPOSURE OF IMMORTALIZED HUMAN ORAL KERATINOCYTES GENERATED PRENEOPLASTIC CELLS WITH EMT AND INCREASED NOX1}

By using the multistep carcinogenesis concept, we first tested whether Nox1 increases neoplastic progression of immortalized human epithelial cells and, if so, whether this process is reversible and/or generates a more invasive phenotype. By selection of cells under a growth constraint, i.e., calciuminduced differentiation, we expected that resistant or selected cells would exhibit increased rates of 
translation of the Nox1 protein. This will allow them to proliferate in high-calcium medium. This study design will shed light on a possible role of Nox1 in an early transformation step beyond the immortalization step.

Human gingival mucosal keratinocytes immortalized with HPV 16 E6/E7 oncogenes (GM16) were utilized as the starting point of the transformation scheme[65]. In our first study, chronic ethanol treatment was chosen for its applicability to ethanol-induced oral cancer (Fig. 2). GM16 cells were cultured in low-calcium keratinocyte medium and exposed to $30 \mathrm{mM}$ ethanol in a closed incubator with ethanol replenishment every week for 9 weeks. The medium of ethanol-treated cells was then changed to DMEM, which caused differentiation-induced cell death, leaving selectable resistant cells to survive and proliferate. Without ethanol treatment or with 3- or 6-week ethanol exposure, no surviving GM16 cells were obtained in DMEM, indicating that prolonged ethanol exposure as a growth constraint was indeed required. Therefore, prolonged stationary cultures can be used to select preneoplastic human cells, which will allow genetic changes in cells affected by ethanol. Prolonged subcultures ( $\sim-8$ months) were carried out in DMEM to obtain sufficient proliferative cell populations, which were separated into two cell phenotypes (Fig. 2). One with epithelium-like morphology (EPI cells) grew anchorage dependently, and the other with spindle-shape fibroblast-like morphology (FIB cells), indicating that these cells had undergone EMT[65]. FIB cells, but not EPI cells, exhibited anchorage-independent growth (AIG). In comparison to EPI cells, the EMT characteristics of FIB cells were characterized by a decrease in the expression of keratins, desmoplakins, and a complete loss of K14. EMT of FIB cells also correlates with an increase in the expression of vimentin and simple epithelial keratin K18. A recent study demonstrated that ROS are a crucial factor to induce the cell-cell dissociation, an initial step of EMT, but does not provide sufficient signals to establish and maintain the EMT[66]. Chronic ethanol treatment combined with the prolonged subcultures may contribute to EMT stability of FIB cells. FIB cells at low passages (p $<22$ ) were unstable, being able to morphologically and functionally revert back to EPI phenotype upon adapting cultures in low-calcium medium, while no reversion was observed in FIB cells at high passages $(p>43)$ [67]. Thus, FIB cells at $p<22$ may be used to test the ability of anticancer drugs to reverse to a nontransformed phenotype.

Both EPI and FIB cells (at their 60-70 passages) did not form tumors in nude mice; thus, they were not yet tumorigenic (FIB cells produced benign cysts). Both EPI and FIB cells were of benign phenotype. FIB cells were more transformed than EPI cells, while EPI cells were more transformed than GM16 cells. Upon passaging, FIB cells acquired the ability to grow in low or an absence of serum, showing a proliferative capacity more than EPI cells (Fig. 3A). EPI and FIB cells were therefore used as model cells to study early steps of transformation in association with Nox1 expression.

\section{Increased Nox1 Expression in FIB Cells}

EPI and FIB cells were used as model cells (FIB being more transformed with AIG) to find an association with Nox1[36]. Nox1 protein levels were determined in membrane fractions. Compared with EPI membranes, FIB membranes possessed a $63-\mathrm{kDa}$ Nox1 protein at higher levels and exhibited a 2.8-fold higher capability for superoxide and hydroxyl radical generation. Both EPI and FIB cells expressed more abundant Nox1 protein at a proliferating stage than that at a quiescent confluent phase. Nuclei isolated from EPI and FIB cells contained a 63-kDa Nox1 protein. Compared with EPI cells, FIB cells expressed elevated levels of Jun N-terminal kinase (JNK) and ERK proteins. JNK2 was constitutively phosphorylated in FIB cells. Nox1 expression in FIB cells appeared to increase upon passaging up to $\mathrm{p}>$ 150. Thus, an association of Nox1 was found in preneoplastic keratinocytes that exhibited EMT. Furthermore, Nox1-dependent ROS mediate in redox-sensitive ERK and JNK signaling at an early stage of transformation beyond the immortalization step of human keratinocytes. 


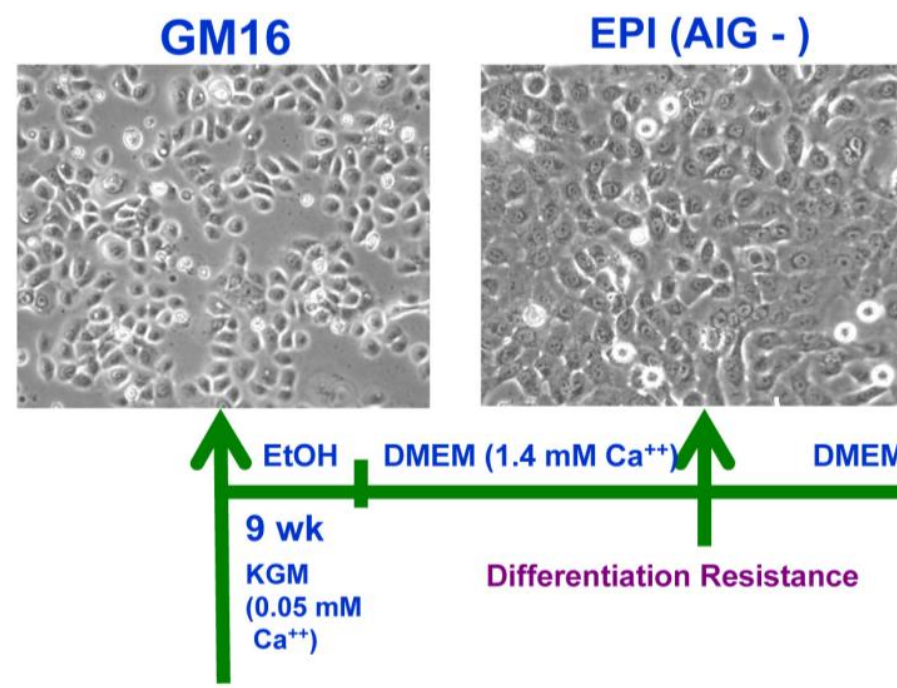

Human gingival

mucosal epithelial cells

Immortalization

(HPV16 E6/E7)
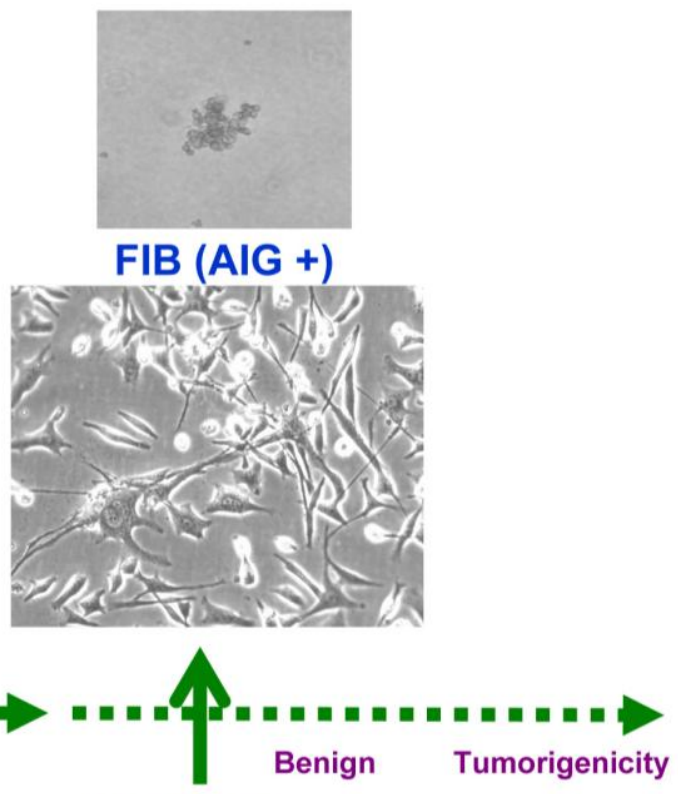

AnchorageIndependent Growth (AIG)

Nox1

ROS, iNOS

pERK, p-JNK

Vimentin, K8/18

FIGURE 2. An experimental design to determine an association of Nox 1 on cell transformation induced by ethanol stress. Immortalized human gingival mucosal keratinocytes (GM16) were exposed to ethanol for 9 weeks, followed by exposure in high calcium in DMEM. Differentiation-resistant cells were resultant preneoplastic cells; EPI and FIB cell lines. FIB cells were capable of growing anchorage independently, thus being more transformed than EPI cells. FIB cells expressed increased Nox1, ROS, and iNOS (inducible nitric oxide synthase) concomitant with an activation of ERK and JNK. Concerning cytoskeletal changes, FIB cells expressed vimentin and simple/fetal epithelial keratins K8/18.

\section{Increased iNOS Expression in FIB Cells}

Hydrogen peroxide is known to induce inducible nitric oxide synthase (iNOS), which is a downstream target gene associated with cancer progression[68]. iNOS is shown to be associated with tumor invasiveness[69]. We studied the expression of redox-sensitive iNOS in these EPI and FIB cells[67]. iNOS at mRNA and protein levels was up-regulated in FIB cells in comparison with EPI cells. FIB cells at low passages $(\mathrm{p}<22)$ were unstable, being able to revert back to the EPI phenotype morphologically and functionally, while no reversion was observed in FIB cells at high passages $(\mathrm{p}>43)$. The morphological reversion of FIB cells was associated with the reversal of vimentin expression as well as AIG. More importantly, these revertants showed reduced levels of iNOS mRNA as well as MAP kinase ERK and phospho-ERK protein expression, while FIB cells without reversion maintained the expression. The MEK1/2 inhibitor U0126 could reduce detectable iNOS mRNA levels, suggesting that MAP kinases were upstream regulators of iNOS transcription. U0126 caused both morphological and functional reversion of FIB cells, indicating involvement of MAP kinases in these functions. 


\section{A. Serum independent growth}

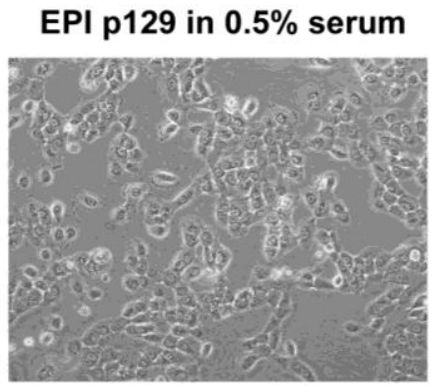

FIB p136 in $0.5 \%$ serum
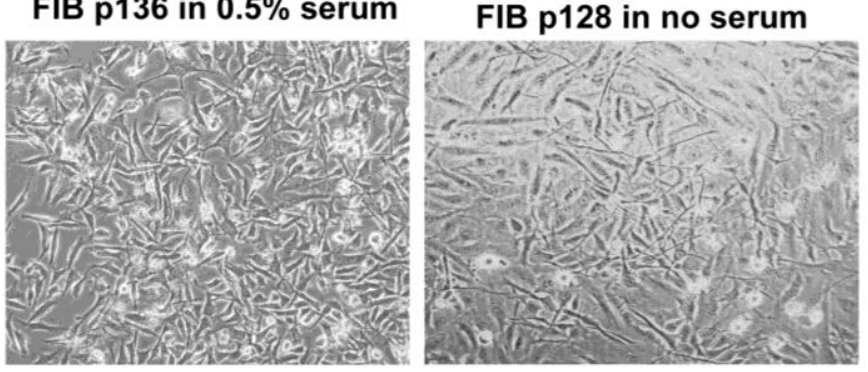

B. Tubulogenesis
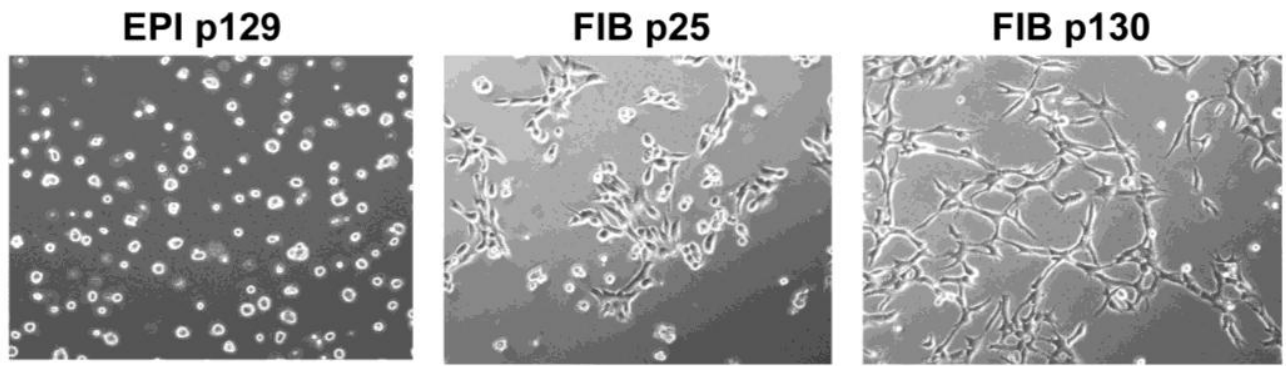

\section{Invasion}
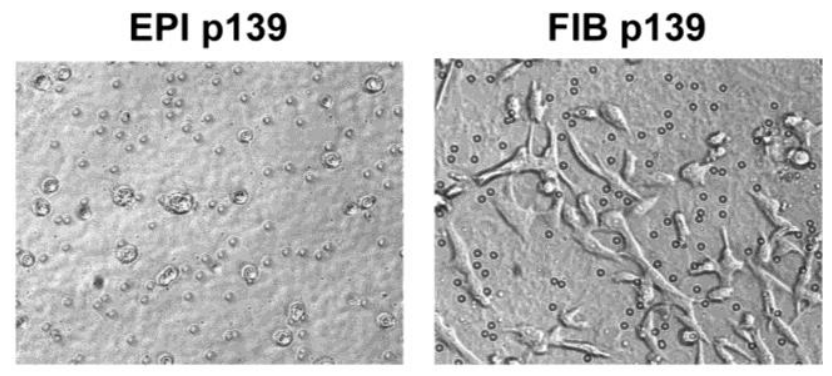

FIGURE 3. Transformation characteristics of FIB cells compared with EPI cells. (A) FIB cells exhibited serumindependent growth better than EPI cells. FIB cells were more proliferative in low and no serum cultures. FIB cells became even more spindle shaped when cultured in no serum. (B) Formation of tubulogenic morphogenesis of FIB cells on Matrigel. EPI and FIB cells at p 129-130 were plated on prepared Matrigel-coated dishes for 4 days in DMEM containing 1\% FCS. FIB cells formed tubules (cords without lumen) with extensive meshwork. (C) By using Boyden chamber assay, FIB cells invaded through filters better than EPI cells.

\section{Branching Morphogenesis of FIB Cells}

Nox1 has been shown to be associated with branching tubulogenic potential as demonstrated in sinusoidal endothelial cells [70]. Indeed, branching morphogenesis is used to characterize breast[71] and prostate[72] cancer cells. We therefore used branching morphogenesis as an indicator of neoplastic transformation. Upon resistance against Matrigel-induced differentiation, FIB cells formed branching tubulogenesis with cords lacking lumen (Fig. 3B). EPI cells formed unproliferative rounded cells as they died off from differentiation when plated on Matrigel. The ability of FIB cells to form branching tubulogenesis bolsters its more transformed phenotype with EMT characteristics. 


\section{Invasiveness and AIG in FIB cells}

ROS have been shown to increase invasive potentials of transformed cells[73]. Nox1-mediated ROS have been recently shown to regulate invasiveness of Ras-induced mouse transformed fibroblasts[54]. FIB cells were AIG positive, being able to grow on semi-solid agar at $2 \%$ efficiency, while EPI cells required anchorage for growth[65]. The EMT phenotype of FIB cells suggests that they are more invasive and metastatic than EPI cells. Using the Boyden invasion chamber, we showed that FIB cells had significant migration through the filters, while EPI cells did not migrate (Fig. 3C). For application purposes, FIB cells were used as model cells for the testing of 2,3-dehydrosilybin (DHS) as an anticancer agent for an inhibition of invasion[74].

\section{Enhanced Migration and MMP-2 and MMP-9 Releases in FIB Cells}

ROS are known to regulate proteins that are important for degradation of extracellular matrices, such as gelatinase matrix MMP-2 and-9, which are key enzymes for degrading type IV collagen and thought to play a critical role in tumor invasion and metastasis[75]. EPI cells secreted latent MMP-9 (92 kDa) (Fig. $4 \mathrm{~A})$. FIB cells released a protein at $86 \mathrm{kDa}$ that was not the active MMP-9 (82 kDa). MMP-9 at $86 \mathrm{kDa}$ is known as an intermediate after first cleavage of latent MMP-9 by MMP-3[76]. FIB cells thus secrete partially active MMP-9 by the action of stromelysin MMP-3, and the implication of MMP-3 in FIB cells is consistent with recent data showing the role of ROS-induced MMP-3 in EMT induction and genomic instability[77]. In the study we carried out to test anticancer effects of DHS[74], EPI and FIB cells were used to determine inhibitory effects of gelatinase (MMP-2 and MMP-9) activities. Expression of MMP-9 has been associated with cell migration of Ras-transfected keratinocytes[78]. We therefore performed wound assays of EPI and FIB cells. FIB cells were capable of migrating into wounds better than EPI cells (Fig. 4B). This bolsters FIB cells as a more transformed phenotype exhibiting greater expression of partially active MMP-9 and cell migration.

\section{Sensitivity of EPI and FIB Cells upon Treatment with Anticancer Drugs}

EPI and FIB cells arose from the same "mother" GM16 cells, with FIB cells being more transformed than EPI cells. Therefore, these cell lines are valuable for testing the effectiveness of anticancer agents. We carried out a comparison study for effectiveness of silybin and DHS by using EPI and FIB cells either by direct treatment[74,79] or sensitization with TNF- $\alpha$ [79]. We found that test agent DHS induced apoptosis in FIB cells, but not in EPI cells. Apoptosis induced by DHS in FIB cells was associated with loss of mitochondrial membrane potentials. Thus, in terms of apoptosis induction by a test agent, EPI and FIB cells may be used to compare anticancer efficacy and specificity of drugs towards a more transformed phenotype.

\section{Association of Antiapoptosis Protein Expression with EMT of FIB Cells}

It has been recognized that inhibitors of apoptosis proteins (IAPs), such as survivin, are markers of multistep malignant development[80,81]. We analyzed expression of survivin and IAPs in EPI and FIB cells (Fig. 5). We found differential expression showing FIB cells expressing increased survivin and cIAP-1 more than EPI cells. No difference in c-IAP-2 was detected. This appears to correlate with higher proliferative growth and EMT, and invasive phenotype of FIB cells. The latter was studied in detail using two more EMT cell lines[82]. 


\section{A. Gelatinase activity}

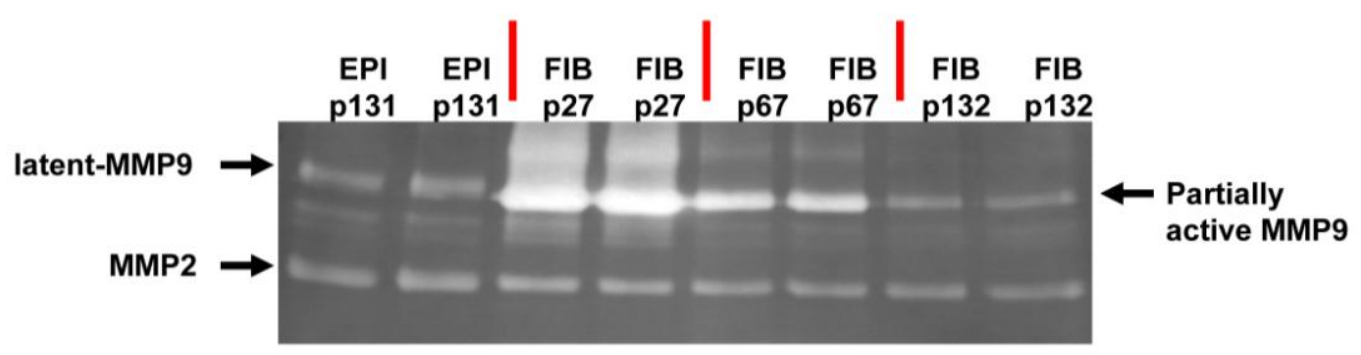

\section{B. Migration}
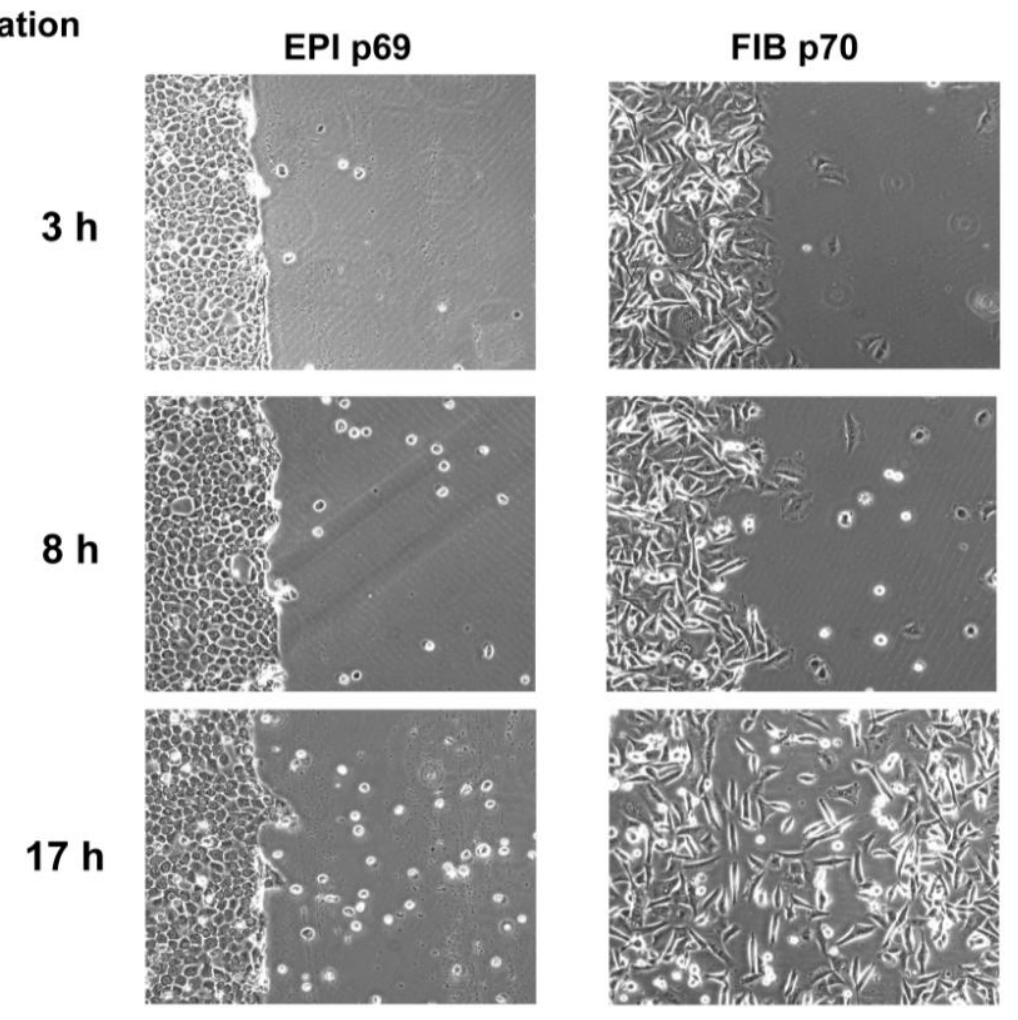

FIGURE 4. Cellular motility of EPI and FIB cells. (A) Gelatinase activity of EPI and FIB cells in conditioned medium after culture for $24 \mathrm{~h}$. FIB cells released partially active MMP-9, while EPI cells released latent MMP-9. (B) In wound assay, FIB cells were more migratory than EPI cells.

\section{Organotypic Cultures of EPI and FIB Cells}

EPI and FIB cells were analyzed in a three-dimensional tissue/epithelial context with respect to the stratified gingival epithelium[83]. In epithelial equivalents, FIB cells exhibited a significant downregulation in K14 and integrin $\alpha 6$ protein, and a loss of E-cadherin, whereas vimentin was increased. FIB epithelial equivalents were devoid of transcripts for E-cadherin. The FIB phenotype exhibited a poor epithelial structure, coinciding with disturbances in the expression of epithelial biomarkers and the persistence of mesenchymal vimentin. Our data indicate that FIB cells share features of EMT and reflect a more progressive stage in epithelial cell transformation. 


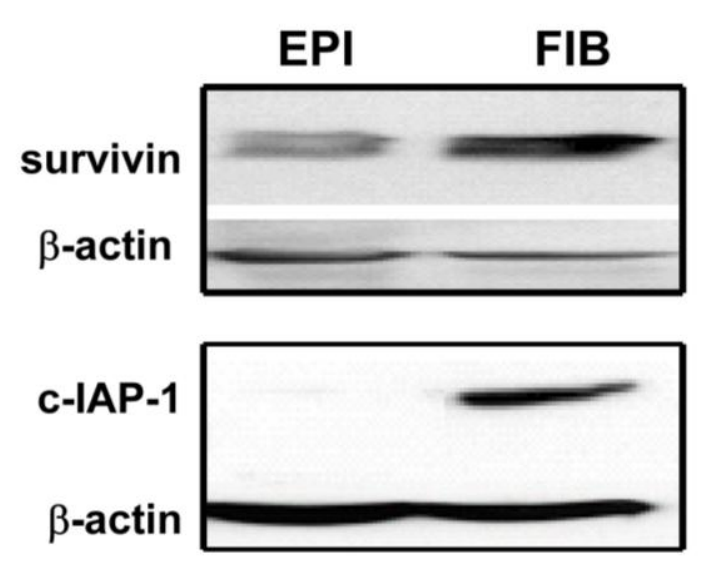

FIGURE 5. Survival and antiapoptosis expression in EPI and FIB cells. FIB cells expressed increased survivin and c-IAP-1 proteins at higher levels than EPI cells.

\section{NOX1 TRANSFECTION OF IMMORTALIZED HUMAN KERATINOCYTES GENERATED PRENEOPLASTIC PROGENITOR CELLS}

We demonstrated that chronic ethanol treatment for 9 weeks rendered selectable preneoplastic EPI and FIB cells, with FIB cells exhibiting EMT and expressing increased Nox1. Thus, an association of Nox1 with preneoplastic EMT cells has been demonstrated. To find whether the EMT phenotype is the result of Nox1 overexpression was our next step[84]. We performed cloning of pcDNA3.1 containing Nox1. Transfections of GM16 keratinocytes with Nox1 plasmid or plasmid alone by using nucleofection or Fugene 6 transfection were carried out. To keep conditions similar to chronic ethanol treatment, we kept transfected cells in culture for a total of 8 weeks with trypsinization only once after the first 4 weeks. Transfected cells were then split 1:2 with one flask for continuation in KGM culture and the other for selection by culturing in DMEM.

Within 7-10 days after DMEM exposure, Nox1-transfected cells produced fast dividing resistant cells. After three more confluence rounds, transfected cells selected in DMEM persistently gave rise to proliferative progenitor cells, so-called Nox1 lines. Five Nox1 lines were reproducibly generated from Nox1-transfected cells: the NuB1 line (first line resulting from nucelofection transfection) was the only line with EMT, and other lines were non-EMT cells. Plasmid transfections did not produce any selectable cells in DMEM. Nox1 lines showed differential mRNA expression of Nox1, Rac1, p47phox, p67phox, NoxO1, and NoxA1 with concomitant increased superoxide generation upon EGF treatment. All five Nox1 lines contained varying amounts of E-cadherin, involucrin, vimentin, and keratins K8/K18. Four non-EMT lines and EPI cells expressed K18, while the EMT NuB1 (similar to FIB) cells expressed vimentin and K8/K18, indicating that this line may be in preneoplastic progression. Our data demonstrated that Nox1 accelerated neoplastic-like progression by inducing generation of progenitor cells. NuB1 indeed expressed antiapoptotic proteins cIAP-1, Bclx, and cdkinase inhibitor $\mathrm{p} 16^{\mathrm{INK} 4 \mathrm{a}}$ and $\mathrm{p} 27^{\mathrm{kip} 1}$ at higher levels than the four non-EMT lines[82]. Thus, NuB1 was the line with an enhanced neoplastic progression similar to FIB cells that were obtained from chronic ethanol treatment of GM16 cells.

\section{CONCLUSIONS}

Our results from chronic ethanol treatment[36,65] and Nox1 overexpression[84] have emphasized the importance of Nox1 in inducing resistance against differentiation-induced cell death and generating selectable preneoplastic human keratinocytes. Our data have also indicated that Nox1 and its oxidants 
contribute to the progression of human keratinocytes during the early stage of cell transformation. As demonstrated in human oral mucosal keratinocytes, Nox1 may also exhibit a capacity to induce an EMT phenotype demonstrating AIG and invasiveness. Finally, the progenitor Nox1-containing cell lines represent model cell lines for comparative investigation between EMT and non-EMT phenotypes, as well as for cytotoxicity tests of anticancer agents.

\section{PERSPECTIVES}

In both studies from chronic ethanol treatment and Nox1 overexpression, progenitor cells with epithelial morphology (non-EMT cells) showed persistent expression of K18, whereas the EMT expressed both K8 and K18. Further questions arise whether Nox1 would play a role in the regulation of these epithelial keratins and, if so, whether the regulation is at transcriptional or post-translational levels. While current studies have demonstrated that Nox1 is able to increase proliferative potentials (i.e., overcoming senescence) of immortalized cells, these Nox1-driven progenitor cells were in the step of enhanced preneoplastic progression. In our experiments, the generation of progenitor cells from immortalized cells arises not just from the presence of Nox 1, but also the requirement of prolonged stationary cultures. This implies that transfection of primary human keratinocytes with Nox1 may extend lifespan, but may not be sufficient to elicit immortality (unless other factors such as Ras are introduced). Thus, Nox1 by itself cannot be considered as an oncogene of human epithelial cancer, but rather a significant contributor or a cofactor of early transformation progression steps in the multistep carcinogenesis.

\section{ACKNOWLEDGMENTS}

The author's research work was supported by the Deutsche Forschungsgemeinschaft (CH288 3-3), Thailand Research Fund/DAAD, and Paul-Erhlich-Society for Chemotherapy. The help of students and trainees W. Chunglok, A. Huber, L. Ersoy, P. Thongphasuk, and A. Sattayakhom is acknowledged.

\section{REFERENCES}

1. Szatrowski, T.P. and Nathan, C.F. (1991) Production of large amounts of hydrogen peroxide by human tumour cells. Cancer Res. 51, 794-798.

2. Gupta, A., Rosenberger, S.F., and Bowden, G.T. (1999) Increased ROS levels contribute to elevated transcription factor and MAP kinase activities in malignantly progressed mouse keratinocyte cell lines. Carcinogenesis 20, 2063-2073.

3. Plak, K., Czarnecka, A.M., Krawczyk, T., Golik, P., and Bartnik, E. (2009) Breast cancer as a mitochondrial disorder. Oncol. Rep. 21, 845-851.

4. Bellance, N., Lestienne, P., and Rossignol, R. (2009) Mitochondria: from bioenergetics to the metabolic regulation of carcinogenesis. Front. Biosci. 14, 4015-4034.

5. Fernandez, C., Sharrard, R.M., Talbot, M., Reed, B.D., and Monks, N. (1995) Evaluation of the significance of polyamines and their oxidases in the aetiology of human cervical carcinoma. Br. J. Cancer 72, 1194-1199.

6. Turner, C.P., Toye, A.M., and Jones, O.T. (1998) Keratinocyte superoxide generation. Free Radic. Biol. Med. 24, 401-407.

7. Sekharam, M., Cunnick, J.M., and Wu, J. (2000) Involvement of lipoxygenase in lysophosphatidic acid-stimulated hydrogen peroxide release in human HaCaT keratinocytes. Biochem. J. 346, 751-758.

8. Suh, Y.A., Arnold, R.S., Lassegue, B., Shi, J., Xu, X., Sorescu, D., Chung, A.B., Griendling, K.K., and Lambeth, J.D. (1999) Cell transformation by the superoxide-generating oxidase Mox1. Nature 401, 79-82.

9. Lambeth, J.D. (2004) NOX enzymes and the biology of reactive oxygen. Nat. Rev. Immunol. 4, 181-189.

10. Lambeth, J.D. (2007) Nox enzymes, ROS, and chronic disease: an example of antagonistic pleiotropy. Free Radic. Biol. Med. 43, 332-347.

11. Jaquet, V., Scapozza, L., Clark, R.A., Krause, K.H., and Lambeth, J.D. (2009) Small-molecule NOX inhibitors: ROSgenerating NADPH oxidases as therapeutic targets. Antioxid. Redox Signal. 11, 2535-2552.

12. Laurent, E., McCoy, J.W., 3rd, Macina, R.A., Liu, W., Cheng, G., Robine, S., Papkoff, J., and Lambeth, J.D. (2008) Nox 1 is over-expressed in human colon cancers and correlates with activating mutations in K-Ras. Int. J. Cancer 123, 
100-107.

13. Lim, S.D., Sun, C., Lambeth, J.D., Marshall, F., Amin, M., Chung, L., Petros, J.A., and Arnold, R.S. (2005) Increased Nox1 and hydrogen peroxide in prostate cancer. Prostate 62, 200-207.

14. Banfi, B., Maturana, A., Jaconi, S., Arnaudeau, S., Laforge, T., Sinha, B., Ligeti, E., Demaurex, N., and Krause, K.H. (2000) A mammalian $\mathrm{H}^{+}$channel generated through alternative splicing of the NADPH oxidase homolog NOH-1. Science 287, 138-142.

15. Kikuchi, H., Hikage, M., Miyashita, H., and Fukumoto, M. (2000) NADPH oxidase subunit, gp91phox homologue, preferentially expressed in human colon epithelial cells. Gene 254, 237-243.

16. Cheng, G., Cao, Z., Xu, X., van Meir, E.G., and Lambeth, J.D. (2001) Homologs of gp91phox: cloning and tissue expression of Nox3, Nox4, and Nox5. Gene 269, 131-140.

17. Arnold, R.S., Shi, J., Murad, E., Whalen, A.M., Sun, C.Q., Polavarapu, R., Parthasarathy, S., Petros, J.A., and Lambeth, J.D. (2001) Hydrogen peroxide mediates the cell growth and transformation caused by the mitogenic oxidase Nox1. Proc. Natl. Acad. Sci. U. S. A. 98, 5550-5555.

18. Arbiser, J.L., Petros, J., Klafter, R., Govindajaran, B., McLaughlin, E.R., Brown, L.F., Cohen, C., Moses, M., Kilroy, S., Arnold, R.S., and Lambeth, J.D. (2002) Reactive oxygen generated by Nox1 triggers the angiogenic switch. Proc. Natl. Acad. Sci. U. S. A. 22, 715-720.

19. Arnold, R.S., He, J., Remo, A., Ritsick, D., Yin-Goen, Q., Lambeth, J.D., Datta, M.W., Young, A.N., and Petros, J.A. (2007) Nox1 expression determines cellular reactive oxygen and modulates c-fos-induced growth factor, interleukin8, and Cav-1. Am. J. Pathol. 171, 2021-2032.

20. Perner, A., Andresen, L., Pedersen, G., and Rask-Madsen, J. (2003) Superoxide production and expression of $\mathrm{NAD}(\mathrm{P}) \mathrm{H}$ oxidases by transformed and primary human colonic epithelial cells. Gut 52, 231-236.

21. Geiszt, M., Lekstrom, K., Brenner, S., Hewitt, S.M., Dana, R., Malech, H.L., and Leto, T.L. (2003) NAD(P)H oxidase 1 , a product of differentiated colon epithelial cells, can partially replace glycoprotein 91phox in the regulated production of superoxide by phagocytes. J. Immunol. 170, 299-306.

22. Fukuyama, M., Rokutan, K., Sano, T., Miyake, H., Shimada, M., and Tashiro, S. (2005) Overexpression of a novel superoxide producing enzyme, NADPH oxidase 1, in adenoma and well differentiated adenocarcinoma of the human colon. Cancer Lett. 221, 97-104.

23. Rokutan, K., Kawahara, T., Kuwano, Y., Tominaga, K., Sekiyama, A., and Teshima-Kondo S. (2006) NADPH oxidases in the gastrointestinal tract: a potential role of Nox1 in innate immune response and carcinogenesis. Antioxid. Redox Signal. 8, 1573-1582.

24. Szanto, I., Rubbia-Brandt, L., Kiss, P., Steger, K., Banfi, B., Kovari, E., Herrmann, F., Hadengue, A., and Krause, K.H. (2005) Expression of NOX1, a superoxide-generating NADPH oxidase, in colon cancer and inflammatory bowel disease. J. Pathol. 207, 164-176.

25. Chamulitrat, W. (1999) Activation of the superoxide-generating NADPH oxidase of intestinal lymphocytes produces highly reactive free radicals from sulfite. Free Radic. Biol. Med. 27, 411-421.

26. Desouki, M.M., Kulawiec, M., Bansal, S., Das, G.M., and Singh, K.K. (2005) Cross talk between mitochondria and superoxide generating NADPH oxidase in breast and ovarian tumors. Cancer Biol. Ther. 4, 1367-1373.

27. Chiera, F., Meccia, E., Degan, P., Aquilina, G., Pietraforte, D., Minetti, M., Lambeth, D., and Bignami, M. (2008) Overexpression of human NOX1 complex induces genome instability in mammalian cells. Free Radic. Biol. Med. 44, 332-342.

28. Geiszt, M., Lekstrom, K., and Leto, T.L. (2004) Analysis of mRNA transcripts from the NAD(P)H oxidase 1 (Nox1) gene. Evidence against production of the NADPH oxidase homolog-1 short (NOH-1S) transcript variant. J. Biol. Chem. 279, 51661-51668.

29. Banfi, B., Clark, R.A., Steger, K., and Krause, K.H. (2003) Two novel proteins activate superoxide generation by the NADPH oxidase NOX1. J. Biol. Chem. 278, 3510-3513.

30. Takeya, R., Ueno, N., Kami, K., Taura, M., Kohjima, M., Izaki, T., Nunoi, H., and Sumimoto, H. (2003) Novel human homologues of p47phox and p67phox participate in activation of superoxide-producing NADPH oxidases. $J$. Biol. Chem. 278, 25234-25246.

31. Geiszt, M., Lekstrom, K., Witta, J., and Leto, T.L. (2003) Proteins homologous to p47phox and p67phox support superoxide production by NAD(P)H oxidase 1 in colon epithelial cells. J. Biol. Chem. 278, 20006-20012.

32. Ambasta, R.K., Kumar, P., Griendling, K.K., Schmidt, H.H, Busse, R., and Brandes, R.P. (2004) Direct interaction of the novel Nox proteins with p22phox is required for the formation of a functionally active NADPH oxidase. J. Biol. Chem. 279, 45935-45941.

33. Nisimoto, Y., Tsubouchi, R., Diebold, B.A., Qiao, S., Ogawa, H., Ohara, T., and Tamura, M. (2008) Activation of NADPH oxidase 1 in tumour colon epithelial cells. Biochem. J. 415, 57-65.

34. Ueyama, T., Geiszt, M., and Leto, T.L. (2006) Involvement of Rac1 in activation of multicomponent Nox1- and Nox3-based NADPH oxidases. Mol. Cell. Biol. 26, 2160-2174.

35. Cheng, G., Diebold, B.A., Hughes, Y., and Lambeth, J.D. (2006) Nox1-dependent reactive oxygen generation is regulated by Rac1. J. Biol. Chem. 281, 17718-17726.

36. Chamulitrat, W., Schmidt, R., Tomakidi, P., Stremmel, W., Chunglok, W., Kawahara, T., and Rokutan, K. (2003) Association of gp91phox homolog Nox1 with anchorage independent growth and MAP Kinase-activation of transformed human keratinocytes. Oncogene 22, 6045-6053. 
37. Hilenski, L.L., Clempus, R.E., Quinn, M.T., Lambeth, J.D., and Griendling, K.K. (2004) Distinct subcellular localizations of Nox1 and Nox4 in vascular smooth muscle cells. Arterioscler. Thromb. Vasc. Biol. 24, 677-683.

38. Park, H.S., Lee, S.H., Park, D., Lee, J.S., Ryu, S.H., Lee, W.J., Rhee, S.G, and Bae, Y.S. (2004) Sequential activation of phosphatidylinositol 3-kinase, beta Pix, Rac1, and Nox1 in growth factor-induced production of H2O2. Mol. Cell. Biol. 24, 4384-4394.

39. Helmcke, I., Heumüller, S., Tikkanen, R., Schröder, K., and Brandes, R.P. (2009) Identification of structural elements in Nox1 and Nox4 controlling localization and activity. Antioxid. Redox Signal. 11, 1279-1287.

40. Goldman, R., Moshonov, S., and Zor, U. (1998) Generation of reactive oxygen species in a human keratinocyte cell line: role of calcium. Arch. Biochem. Biophys. 350, 10-18.

41. Yang, J.-Q., Li, S., Domann, F.E., Buettner, G.R., and Oberley, L.W. (1999) Superoxide generation in v-Ha-rastransduced human keratinocyte HaCaT cells. Mol. Carcinog. 26, 180-188.

42. Hsu, T.C., Young, M.R., Cmarik, J., and Colburn, N.H. (2000) Activator protein 1 (AP-1)- and nuclear factor kappaB (NF-kappaB)-dependent transcriptional events in carcinogenesis. Free Radic. Biol. Med. 28, 1338-1348.

43. Li, J.J., Cao, Y., Young, M.R., and Colburn, N.H. (2000) Induced expression of dominant-negative c-jun downregulates NFkappaB and AP-1 target genes and suppresses tumor phenotype in human keratinocytes. Mol. Carcinog. 29, 159-169.

44. Finch, J.S., Tome, M.E., Kwei, K.A., and Bowden, G.T. (2006) Catalase reverses tumorigenicity in a malignant cell line by an epidermal growth factor receptor pathway. Free Radic. Biol. Med. 40, 863-875.

45. Burch, P.M., and Heintz, N.H. (2005) Redox regulation of cell-cycle re-entry: cyclin D1 as a primary target for the mitogenic effects of reactive oxygen and nitrogen species. Antioxid. Redox Signal. 7, 741-751.

46. Ranjan, P., Anathy, V., Burch, P.M., Weirather, K., Lambeth, J.D., and Heintz, N.H. (2006) Redox-dependent expression of cyclin D1 and cell proliferation by Nox1 in mouse lung epithelial cells. Antioxid. Redox Signal. 8, 1447-1459.

47. Adachi, Y., Shibai, Y., Mitsushita, J., Shang, W.H., Hirose, K., and Kamata, T. (2008) Oncogenic Ras upregulates NADPH oxidase 1 gene expression through MEK-ERK-dependent phosphorylation of GATA-6. Oncogene 27, 4921-4923.

48. Shinohara, M., Shang, W.H., Kubodera, M., Harada, S., Mitsushita, J., Kato, M., Miyazaki, H., Sumimoto, H., and Kamata, T. (2007) Nox1 redox signaling mediates oncogenic Ras-induced disruption of stress fibers and focal adhesions by down-regulating Rho. J. Biol. Chem. 282, 17640-17648.

49. Gianni, D., Bohl, B., Courtneidge, S.A., and Bokoch, G.M. (2008) The involvement of the tyrosine kinase c-Src in the regulation of reactive oxygen species generation mediated by NADPH oxidase-1. Mol. Biol. Cell 19, 2984-2994.

50. Sadok, A., Bourgarel-Rey, V., Gattacceca, F., Penel, C., Lehmann, M., and Kovacic, H. (2008) Nox1-dependent superoxide production controls colon adenocarcinoma cell migration. Biochim. Biophys. Acta 1783, $23-33$.

51. Sadok, A., Pierres, A., Dahan, L., Prévôt, C., Lehmann, M., and Kovacic, H. (2009) NADPH oxidase 1 controls the persistence of directed cell migration by a Rho-dependent switch of alpha2/alpha3 integrins. Mol. Cell. Biol. 29 , 3915-3928.

52. Schröder, K., Helmcke, I., Palfi, K., Krause, K.H., Busse, R., and Brandes, R.P. (2007) Nox1 mediates basic fibroblast growth factor-induced migration of vascular smooth muscle cells. Arterioscler. Thromb. Vasc. Biol. 27, 1736-1743.

53. Weber, D.S., Taniyama, Y., Rocic, P., Seshiah, P.N., Dechert, M.A., Gerthoffer, W.T., and Griendling, K.K. (2004) Phosphoinositide-dependent kinase 1 and p21-activated protein kinase mediate reactive oxygen species-dependent regulation of platelet-derived growth factor-induced smooth muscle cell migration. Circ. Res. 94, 1219-1226.

54. Shinohara, M., Adachi, Y., Mitsushita, J., Kuwabara, M., Nagasawa, A., Harada, S., Furuta, S., Zhang, Y., Seheli, K., Miyazaki, H., and Kamata, T. (2010) Reactive oxygen generated by NADPH oxidase 1 (nox1) contributes to cell invasion by regulating matrix metalloprotease-9 production and cell migration. J. Biol. Chem. 285, 4481-4488.

55. Chamulitrat, W., Stremmel, W., Kawahara, T., Rokutan, K., Fujii, H., Wingler, K., Schmidt, H.H., and Schmidt, R. (2004) A constitutive NADPH oxidase-like system containing gp91phox homologs in human keratinocytes. J. Invest. Dermatol. 122, 1000-1009.

56. Valencia, A. and Kochevar, I.E. (2008) Nox1-based NADPH oxidase is the major source of UVA-induced reactive oxygen species in human keratinocytes. J. Invest. Dermatol. 128, 214-222.

57. Rheinwald, J.G. and Beckett, M.A. (1980) Defective terminal differentiation in culture as a consistent and selectable character of malignant human keratinocytes. Cell 22, 629-632.

58. Rubin, A.L. and Ellison, B.J. (1991) Induction of transformation in NIH3T3 cells by moderate growth constraint: evidence that neoplasia is driven by adaptational change. Carcinogenesis 12, 1801-1806.

59. Lee, L.W., Tsao, M.S., Grisham, J.W., and Smith, G.J. (1989) Emergence of neoplastic transformants spontaneously or after exposure to N-methyl-N'-nitro-N-nitrosoguanidine in populations of rat liver epithelial cells cultured under selective and nonselective conditions. Am. J. Pathol. 135, 63-71.

60. Rhim, J.S., Yoo, J.H., Park, J.H., Thraves, P., Salehi, Z., and Dritschilo, A. (1990) Evidence for the multistep nature of in vitro human epithelial cell carcinogenesis. Cancer Res. 50, 5653S-5657S.

61. Michelle, Y., Matte, A.D., Moses-Soto, H., and Kruk, P.A (2002) Calcium-mediated telomerase activity in ovarian epithelial cells. Arch. Biochem. Biophys. 399, 239-244.

62. Kulesz-Martin, M., Kilkenny, A.E., Holbrook, K.A., Digernes, V., and Yuspa, S.H. (1983) Properties of carcinogen altered mouse epidermal cells resistant to calcium-induced terminal differentiation. Carcinogenesis 4, 1367-1377. 
63. Sherman, L. and Schlegel, R. (1996) Serum- and calcium-induced differentiation of human keratinocytes is inhibited by the E6 oncoprotein of human papillomavirus type 16. J. Virol. 70, 3269-3279.

64. Karen, J., Wang, Y., Javaherian, A., Vaccariello, M., Fusenig, N.E., and Garlick, J.A. (1999) 12-Otetradecanoylphorbol-13-acetate induces clonal expansion of potentially malignant keratinocytes in a tissue model of early neoplastic progression. Cancer Res. 59, 474-481.

65. Chamulitrat, W., Schmidt, R., Chunglok, W., and Tomakidi, P. (2003) Epithelium-like and fibroblast-like phenotypes derived from HPV16 E6/E7-immortalized human gingival keratinocytes following chronic ethanol treatment. Eur. J. Cell Biol. 82, 313-322.

66. Inumaru, J., Nagano, O., Takahashi, E., Ishimoto, T., Nakamura, S., Suzuki, Y., Niwa, S., Umezawa, K., Tanihara, H., and Saya, H. (2009) Molecular mechanisms regulating dissociation of cell-cell junction of epithelial cells by oxidative stress. Genes Cells 14, 703-716.

67. Chunglok, W., Ittarat, W., Tomakidi, P., Schmidt, R., Stremmel, W., and Chamulitrat, W. (2004) Human gingival mucosal keratinocytes exhibiting anchorage-independent growth express increased inducible nitric oxide synthase: regulation by MAP kinases. Nitric Oxide 11, 237-246.

68. Ambs, S., Merriam, W.G., Bennett, W.P., Felley-Bosco, E., Ogunfusika, M.O., Oser, S.M., Klein, S., Shields, P.G., Billiar, T.R., and Harris, C.C. (1998) Frequent nitric oxide synthase-2 expression in human colon adenomas: implication for tumor angiogenesis and colon cancer progression. Cancer Res. 58, 334-341.

69. Orucevic, A., Bechberge, J.R, Green, A.M., Shapiro, R.A., Billiar, T.R., and Lala, P.K. (1999) Nitric-oxide production by murine mammary adenocarcinoma cells promotes tumor-cell invasiveness. Int. J. Cancer 81, 889-896.

70. Kobayashi, S., Nojima, Y., Shibuya, M., and Maru, Y. (2004) Nox1 regulates apoptosis and potentially stimulates branching morphogenesis in sinusoidal endothelial cells. Exp. Cell Res. 300, 455-462.

71. Michaelson, J.S., Cho, S., Browning, B., Zheng, T.S., Lincecum, J.M., Wang, M.Z., Hsu, Y.M., and Burkly, L.C. (2005) Tweak induces mammary epithelial branching morphogenesis. Oncogene 24, 2613-2624.

72. Wang, B.E., Wang, X.D., Ernst, J.A., Polakis, P., and Gao, W.Q. (2008) Regulation of epithelial branching morphogenesis and cancer cell growth of the prostate by Wnt signaling. PLoS One 3, e2186.

73. Mori, K., Shibanuma, M., and Nose, K. (2004) Invasive potential induced under long-term oxidative stress in mammary epithelial cells. Cancer Res. 64, 7464-7472.

74. Huber, A., Thongphasuk, P., Erben, G., Lehmann, W.D., Tuma, S., Stremmel, W., and Chamulitrat, W. (2008) Significantly greater antioxidant anticancer activities of 2,3-dehydrosilybin than silybin. Biochim. Biophys. Acta 1780, 837-847.

75. Waas, E.T., Wobbes, T., Lomme, R.M., DeGroot, J., Ruers, T., and Hendriks, T. (2003) Matrix metalloproteinase 2 and 9 activity in patients with colorectal cancer liver metastasis. Br. J. Surg. 90, 1556-1564.

76. Ogata, Y., Enghild, J.J., and Nagase, H. (1992) Matrix metalloproteinase 3 (stromelysin) activates the precursor for the human matrix metalloproteinase 9. J. Biol. Chem. 267, 3581-3584.

77. Radisky, D.C., Levy, D.D., Littlepage, L.E., Liu, H., Nelson, C.M., Fata, J.E., Leake, D., Godden, E.L., Albertson, D.G., Nieto, M.A., Werb, Z., and Bissell, M.J. (2005) Rac1b and reactive oxygen species mediate MMP-3-induced EMT and genomic instability. Nature 436, 123-127.

78. Charvat, S., Chignol, M.C., Souchier, C., Le Griel, C., Schmitt, D., and Serres, M. (1998) Cell migration and MMP-9 secretion are increased by epidermal growth factor in HaCaT-ras transfected cells. Exp. Dermatol. 7, 184-190.

79. Thongphasuk, P., Stremmel, W., and Chamulitrat, W. (2008) Potent direct or TNF-alpha-promoted anticancer effects of 2,3-dehydrosilybin: comparison study with silybin. Chemotherapy 54, 23-30.

80. Zangemeister-Wittke, U. and Simon, H.U. (2004) An IAP in action: the multiple roles of survivin in differentiation, immunity and malignancy. Cell Cycle 3, 1121-1123.

81. Liu, Z., Li, H., Derouet, M., Filmus, J., LaCasse, E.C., Korneluk, R.G., Kerbel, R.S., and Rosen, K.V. (2005) ras Oncogene triggers up-regulation of cIAP2 and XIAP in intestinal epithelial cells: epidermal growth factor receptordependent and -independent mechanisms of ras-induced transformation. J. Biol. Chem. 280, 37383-37392.

82. Chamulitrat, W., Sattayakhom, A., Herold-Mended, C., and Stremmel, W. (2009) Human papillomavirus 16 E6/E7immortalized human gingival keratinocytes with epithelial mesenchymal transition acquire increased expression of cIAP-1, Bclx and p27(Kip1). Exp. Dermatol. 18, 1067-1069.

83. Müssig, E., Steinberg, T., Kohl, A., Chamulitrat, W., Komposch, G., and Tomakidi, P. (2008) Discrimination of epithelium-like and fibroblast-like phenotypes derived from ethanol-treated immortalised human gingival keratinocytes in epithelial equivalents. Cell Tissue Res. 332, 57-71.

84. Chamulitrat, W., Huber, A., Riedel, H.D., and Stremmel, W. (2007) Nox1 induces differentiation resistance in immortalized human keratinocytes generating cells that express simple epithelial keratins. J. Invest. Dermatol. 127, 2171-2183.

\section{This article should be cited as follows:}

Chamulitrat, W. (2010) Role of gp91phox homolog Nox1 in induction of premalignant spindle phenotypes of HPV 16 E6/E7immortalized human keratinocytes. TheScientificWorldJOURNAL 10, 1435-1449. DOI 10.1100/tsw.2010.131. 

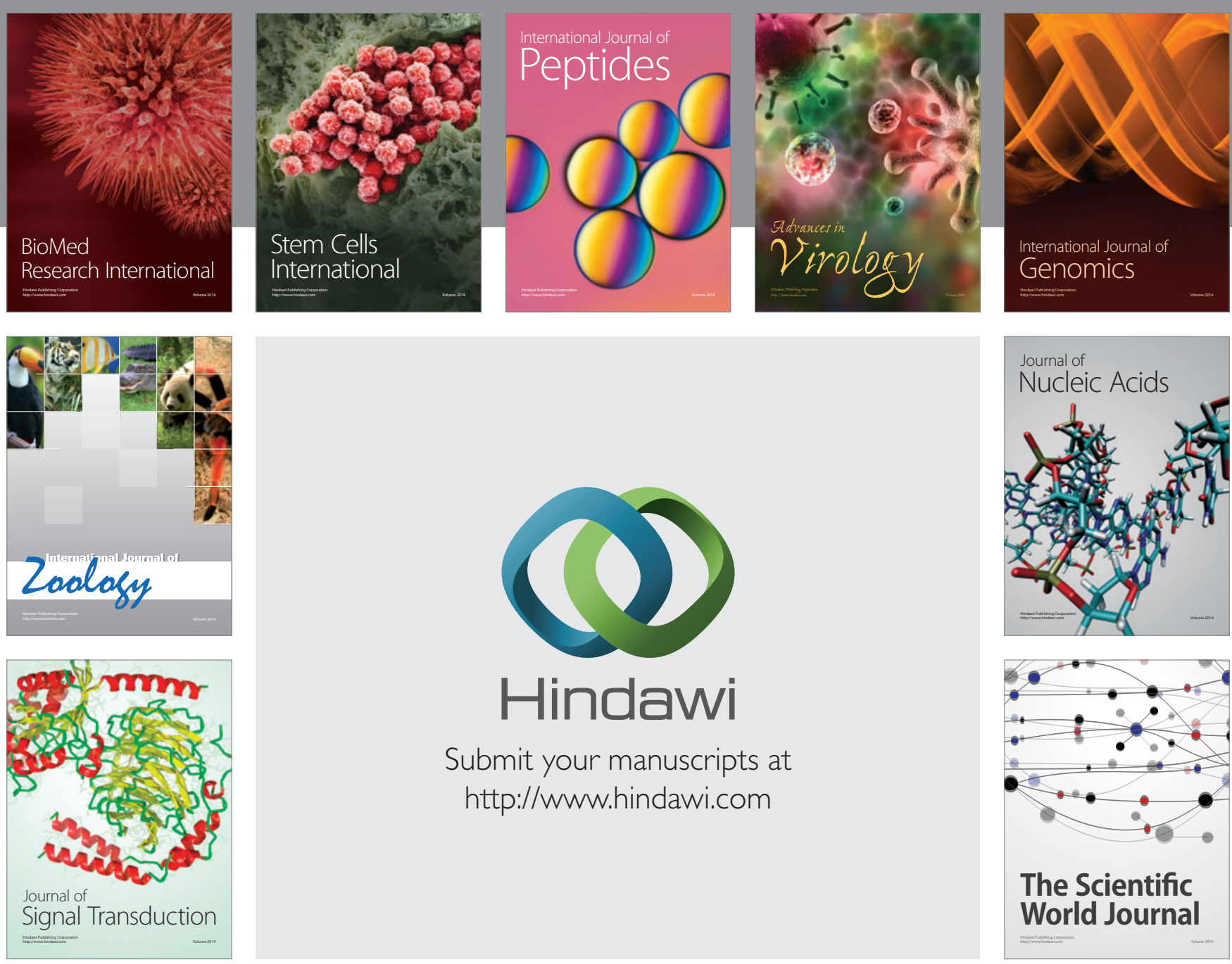

Submit your manuscripts at

http://www.hindawi.com
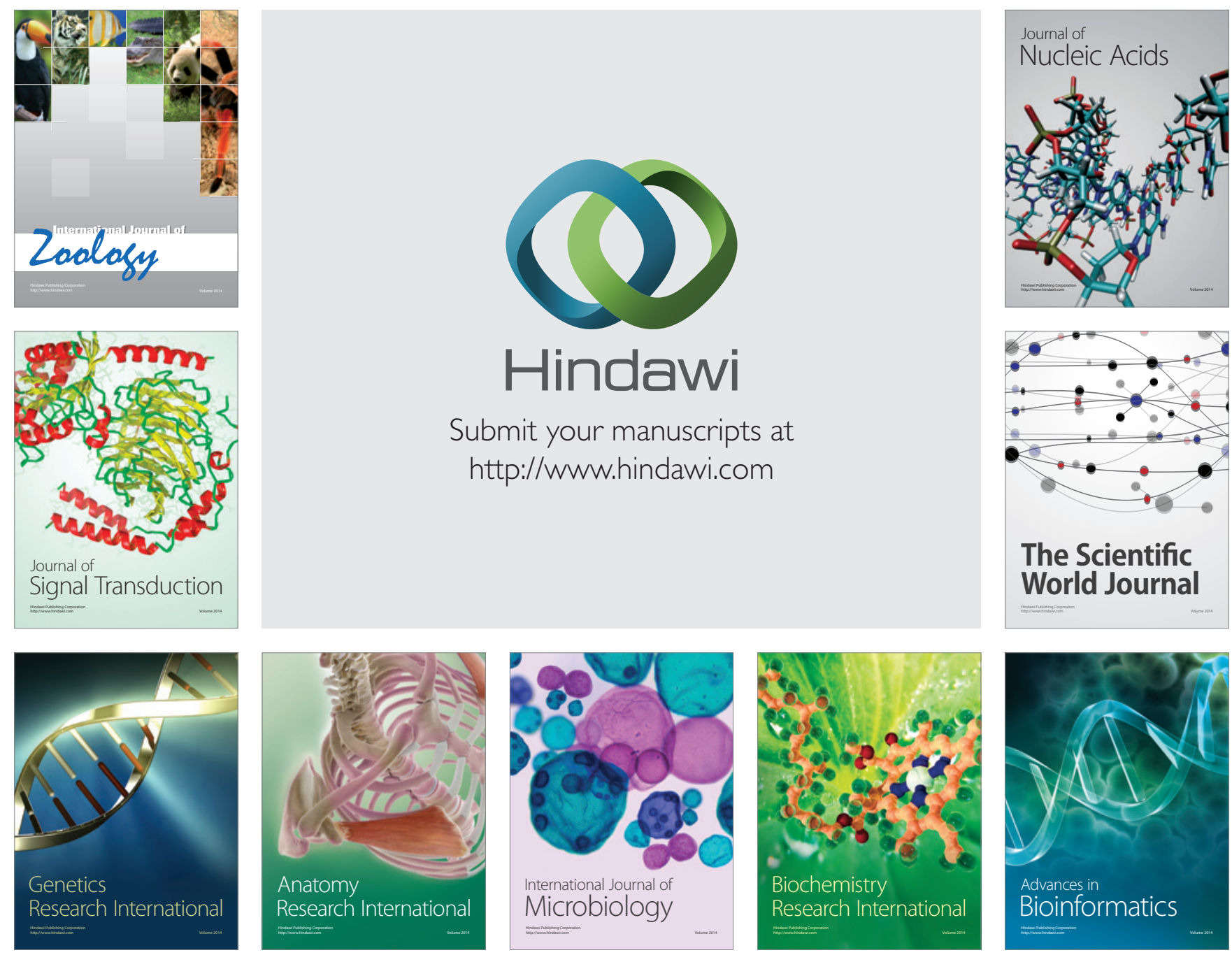

The Scientific World Journal
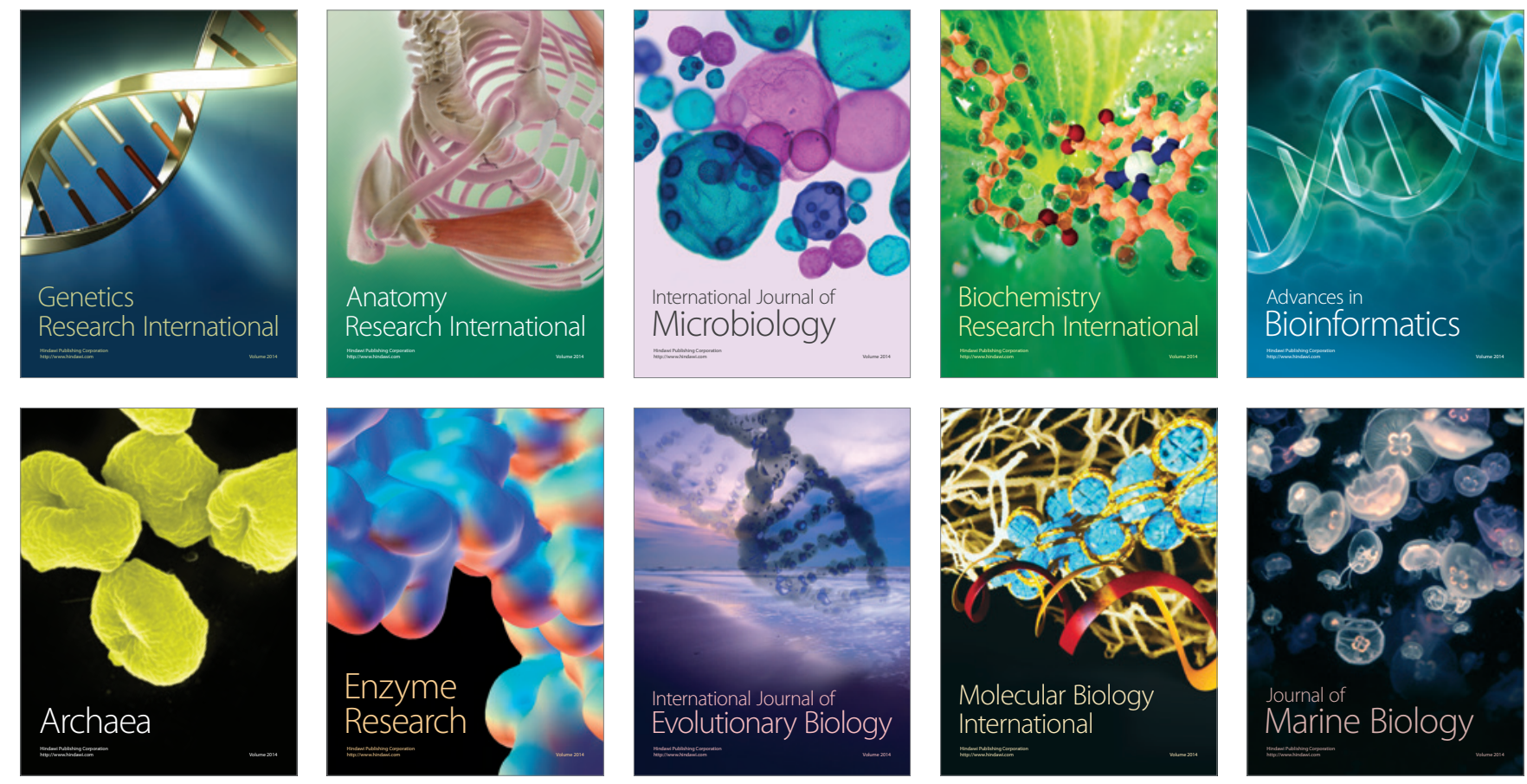